\title{
Bladder Cancer pT2 TNM Finding v7
}

National Cancer Institute

\section{Source}

National Cancer Institute. Bladder Cancer PT2 TNM Finding v7. NCI Thesaurus. Code C89352.

Bladder cancer with tumor invading the muscularis propria. (from AJCC 7th Ed.) 